\title{
Bacteria Supported on Carbon-Coated Monoliths for Water Denitrification
}

\author{
David Espinosa-Iglesias 1, ${ }^{\dagger}$, Esther Bailón-García ${ }^{1,2}$, Ma Isidora Bautista-Toledo ${ }^{1}$, \\ Francisco Carrasco-Marín 1,2 1 and Agustín F. Pérez-Cadenas $1,2, *$ (I) \\ 1 Carbon Materials Research Group, Inorganic Chemistry Department, Faculty of Sciences, \\ University of Granada, Campus Fuentenueva s/n, ES18071 Granada, Spain; \\ despinosa@cosentino.com (D.E.-I.); estherbg@ugr.es (E.B.-G.); bautista@ugr.es (M.I.B.-T.); \\ fmarin@ugr.es (F.C.-M.) \\ 2 Unit of Excellence in Chemistry Applied to Biomedicine and the Environment of the University of Granada, \\ ES18071 Granada, Spain \\ * Correspondence: afperez@ugr.es; Tel.: +34-958-243-316 \\ † Actual address: Cosentino S.A., ctra Baza-Huércal Overa, Km 59, 04850 Cantoria, Almería, Spain.
}

Received: 4 November 2020; Accepted: 23 November 2020; Published: 24 November 2020

\begin{abstract}
Escherichia coli bacteria were grown inside the channels of cordierite monoliths previously coated with a very good adhered carbon layer. These monolithic structures were tested at room temperature for the nitrate elimination of water solutions working as a batch monolithic bioreactor and showed very good results, as $100 \%$ of the nitrates and nitrites were completely removed in the used experimental conditions. Different rate flows of bacteria growth and nitrate elimination were studied, showing that the higher the flow velocity, the faster the nitrate elimination. Finally, the reproducibility tests confirmed the good performance of the proposed bioreactor.
\end{abstract}

Keywords: carbon-coated monoliths; bacteria; water treatments; nitrate removal

\section{Introduction}

High nitrate amounts in water provoke the overpopulation of some aquatic plants, because these have a lot of nitrogen available for their growth, producing the eutrophication in rivers and lakes, as well as the proliferation of harmful microalgae [1,2]. On the other hand, it has been shown that Escherichia coli supported on activated carbons is an efficient option for water denitrification treatments [3]. In recent years, research on carbon coatings applied on different structural materials, [4] such as honeycomb monoliths, concretes or foams, is gaining attention due to their potential environmental remediation possibilities [5], e.g., biological applications, adsorption, or catalysis. Monolithic structures with multiple channels are especially recommended for liquid phase catalytic processes [6] due to several advantages, such as low pressure drop, easy replacement, high mechanical stability and good heat and mass transfer. Besides, 3D impression technologies have emerged as an interesting tool to design monoliths with specific configurations which improve the active phase performance in several catalytic reactions [7]; in this line, asymmetrical honeycomb monoliths using 3D templates designed and printed by 3D printing technology have been recently prepared [8]. This work collects the results obtained from the preparation of bacteria E. coli supported on carbon coated monoliths and the study of its behavior in the denitrification of water solutions in anaerobic conditions as a first and new approach. For this proposal, cordierite monoliths were coated with carbon and used as E. coli supports, forming a monolithic bioreactor, and its catalytic performance at different flow velocities of both bacteria growth and nitrate elimination was studied. 


\section{Materials and Methods}

Carbon-coated monoliths (Figure 1a) were prepared as follows: cordierite monoliths of $5 \mathrm{~cm}$ in length, $1 \mathrm{~cm}$ in diameter and 31 cells $\mathrm{cm}^{-2}$ (200 cpsi) of cell density were dipped into a polyfurfuryl alcohol (PFA) resin. [9]. They were subsequently cured at room temperature for $24 \mathrm{~h}$ and carbonized at $1173 \mathrm{~K}$ for $1 \mathrm{~h}$ in Ar flow with a heat rate of $2 \mathrm{~K} \mathrm{~min}^{-1}$. After dipping the monoliths in the PFA resin, the monoliths were cured under rotation in the horizontal position to avoid channel blocking. The textural and chemical properties of the carbon-coated monoliths were studied by $\mathrm{N}_{2}$ adsorption at $77 \mathrm{~K}$, temperature programmed desorption (TPD) and scanning electron microscopy (SEM). The porous characteristics were studied using an Autosorb-1C Quantachrome, and applying BET and Dubinin-Radushkevich (DR) equations to the $\mathrm{N}_{2}$ adsorption data. The morphology of the samples was characterized using a ZEISS DSM 950 (30 kV, Göttingen, Germany) scanning electron microscope. The total oxygen content of the carbon layer was determined by TPD $\left(\mathrm{O}_{\mathrm{TPD}}\right)$ heating the samples with a heating rate of $20 \mathrm{~K} \mathrm{~min}^{-1}$ to $1273 \mathrm{~K}$ in He flow and using a Thermocube model quadrupole mass spectrometer (Balzers, Asslar, Germany) to monitor the amount of evolved gases as a function of temperature.

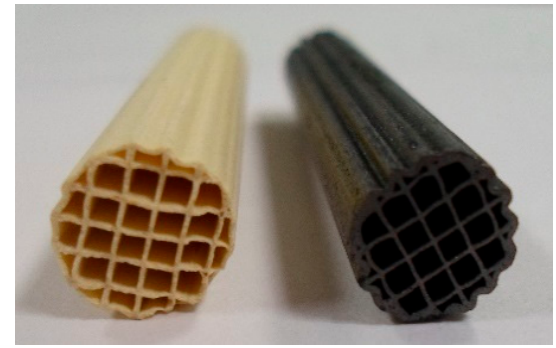

(a)

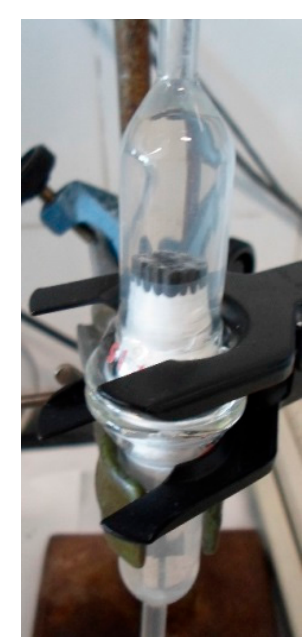

(b)

Figure 1. (a) Cordierite (left) and carbon-coated monoliths (right). (b) Monolithic compartment of the bioreactor.

The bacterium used in this work was Escherichia coli, ATCC 25,922 strain, which was immobilized on the monoliths after its incubation, use and special re-circulating setup where the monolith was well fitted and the bacteria suspension was forced by internal recycling through the channels of the monoliths. The incubation was carried out at $310 \mathrm{~K}$ for 2 days in $50 \mathrm{~mL}$ of tryptic soy broth (TSB) media buffered at $\mathrm{pH} 7$ in sterile conditions and aerobic medium. Then, $1 \mathrm{~mL}$ of this suspension was added to another that contained the monolith in $200 \mathrm{~mL}$ of TSB, recirculating this new suspension through the monolithic channels at $310 \mathrm{~K}$ for $72 \mathrm{~h}$. For this preparation, two different flow rates, 4.6 or $9.2 \mathrm{~cm}^{3} \mathrm{~min}^{-1}$, were used. After this time, the monolith with the immobilized bacteria was separated and washed many times with sterilized distilled water. Bacteria supported into the monoliths were used for the denitrification of $200 \mathrm{~mL}$ of a sterilized nitrate solution of $40 \mathrm{mg} \mathrm{L}^{-1}$ where ethanol was also added as carbon source. The solutions were buffered at $\mathrm{pH} 7 \mathrm{using}$ a phosphate solution. Denitrification processes were carried out at room temperature using a re-circulating setup working as a batch monolithic bioreactor and bubbling argon to guarantee the anaerobic conditions of the media. Nitrite and nitrate concentrations were monitored frequently over several days. The concentration of nitrate was directly analyzed in the bioreactor setup with a selective electrode. The concentration of nitrites was analyzed, taking aliquots from the reaction media. Nitrite concentration was determined at 
$543 \mathrm{~nm}$ after coupling diazotized sulphanilamide with $\mathrm{N}$-(1-naphthyl)-ethylenediamine, using a Hitachi model U 2000 spectrophotometer. Schematically, the bioreactor was composed of two compartments connected by a recirculation flow pump. In one of them, the monolith was fixed in such a way that the nitrate solution would pass through its channels (Figure 1b). In the second compartment, the selective nitrate electrode, the argon inlet and purge, and the aliquot collection for nitrite analysis were placed. In order to study the effect of the flow rate on the denitrification process, three different flow rates were used: $4.6,9.2$ and $13.8 \mathrm{~cm}^{3} \mathrm{~min}^{-1}$. Finally, in order to identify the experimental conditions used in each denitrification experiment, a double number system was established: for example, condition 4.6-4.6 means that the bacteria growth (first number) and denitrification process (second number) were carried out using a flow rate of $4.6 \mathrm{~cm}^{3} \mathrm{~min}^{-1}$.

\section{Results and Discussion}

Cordierite monoliths were completely coated with a very-well adhered carbon layer (Figure 1a). The carbon loading was around a $10.5 \mathrm{wt} . \%$ of the coated monolith, and the carbon layer had an average thickness of $7 \mu \mathrm{m}$. The carbon layer did not have well-developed porosity (Table 1), but its thickness allowed part of the macroporosity and roughness of cordierite to be kept open and covered, enabling E. coli to be retained and form colonies (Figure 2). On the other hand, the oxygen content of the carbon layer determined by TPD was around $9.0 \mathrm{wt} . \%$. Bacteria E. coli were grown inside the monolithic channels of the carbon-coated monoliths to be used in the water denitrification tests. This bacterium was selected because $E$ coli are very common in all urban wastewaters. In addition, these bacteria were also grown inside the monolithic channels of pure cordierite monoliths as reference in order to evaluate the effect of the carbon coating in this application.

Table 1. Textural and chemical characteristics of the carbon coating.

\begin{tabular}{cccc}
\hline $\begin{array}{c}\text { Thickness } \\
(\mu \mathrm{m})\end{array}$ & $\begin{array}{c}\text { OTPD }_{\text {TPt. })} \\
(\mathbf{w t})\end{array}$ & $\begin{array}{c}\mathrm{S}_{\text {BET }} \\
\mathbf{m}^{\mathbf{2}} \mathbf{g}^{\mathbf{1}}\end{array}$ & $\begin{array}{c}\mathbf{V}_{\text {MICRO-N2 }} \\
\mathbf{m m}^{\mathbf{3}} \mathbf{g}^{-\mathbf{1}}\end{array}$ \\
\hline 7 & 9.0 & 64.4 & 30.4 \\
\hline
\end{tabular}
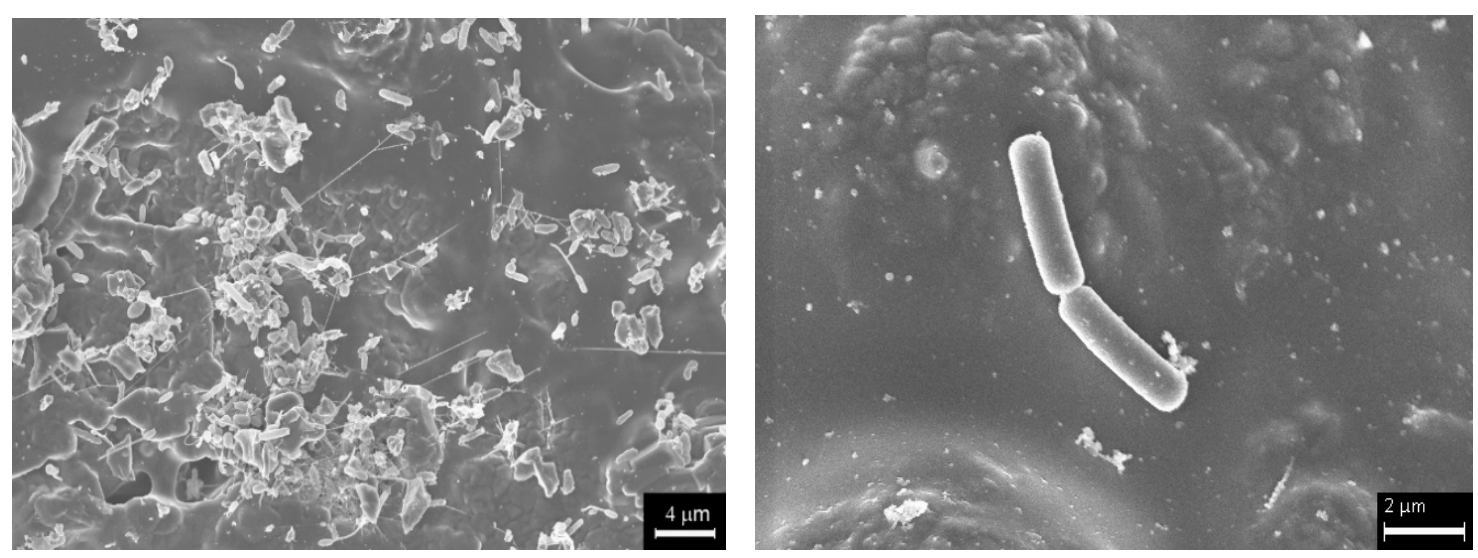

Figure 2. SEM pictures of Escherichia coli on the carbon layer of the monolithic channels.

The results obtained corresponding to the nitrate elimination when bacteria supported on carbon coated monoliths were tested in the denitrification reaction using 4.6-4.6 conditions are displayed in Figure 3. During the denitrification process, in the first step, bacteria transform the nitrates into nitrites, and later the nitrites are removed progressively, this mechanism being very well-known [10]. However, it should be remarked that the good results of nitrate elimination obtained with carbon-coated monoliths working as a batch monolithic bioreactor are completely new in the literature. Moreover, the biocatalytic behaviour of the carbon-coated monolith is much more effective than the pure cordierite monolith, as the full transformation of nitrate occurred $25 \mathrm{~h}$ before (Figure 4 ) when taking into account 
the used experimental conditions. This good compatibility between E. coli growth and carbon supports with different oxygen contents was studied and discussed in a previous work [10], as well as the role of different inorganic supports for this application [11]. The main goal of this study, however, was to show that this carbon-based monolithic bioreactor setup works, and it works very well since $100 \%$ of the nitrates and nitrites were completely removed in the used experimental conditions. Moreover, when different flow rates of denitrification were tested, the response was similar to what can be expected from a non-biological reactor, that is, the higher the flow velocity, the faster the nitrate elimination (Figure 5). Besides, a very interesting result was the fact that when the E. coli growth was carried out faster, 9.2 vs. $4.6 \mathrm{~cm}^{3} \mathrm{~min}^{-1}$, the later nitrate elimination time was much shorter when compared to similar reaction flow rates (see curves 9.2-9.2 vs. 4.6-9.2, Figure 5). This suggests that although bacteria can exist everywhere on the monolithic bioreactor compartments, those adhered on the monolithic channels are crucial for this water treatment application, and, therefore, the control of bacterial growth in the channels should be an important parameter to be taken into account in future work to avoid blocking them [12]. Finally, and no less important, Figure 6 shows the reproducibility test carried out with different rate flows. These results clearly show that carbon-coated monoliths are very interesting structures as support of bacteria E. coli for nitrate removal from water solutions.

We are conscious that a more deep study is required to optimize this bioreactor configuration in different aspects, but this first approach provides a very interesting way since very new techniques, such as 3D impression, may provide assistance in the design of special monoliths in whose channels one can find optimized holes and places where each type of bacterium can grow, therefore enlarging the possibilities and performance of biocatalytic applications.

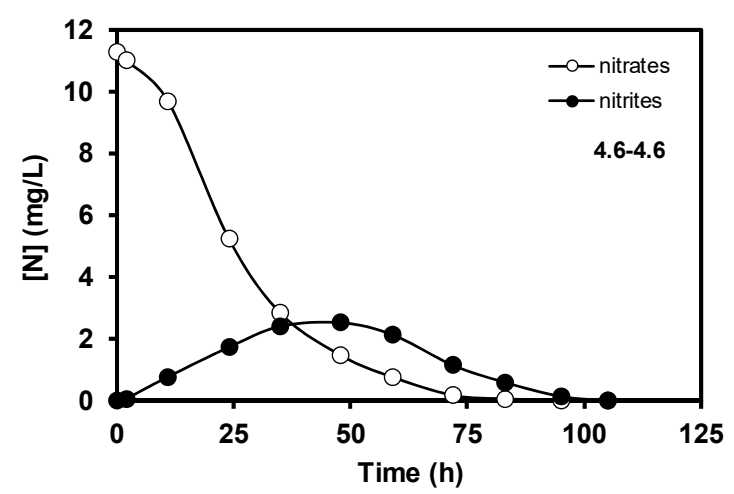

Figure 3. Nitrate and nitrite elimination curves obtained with the carbon-coated monolith in conditions 4.6-4.6. Data are expressed as nitrogen concentration.

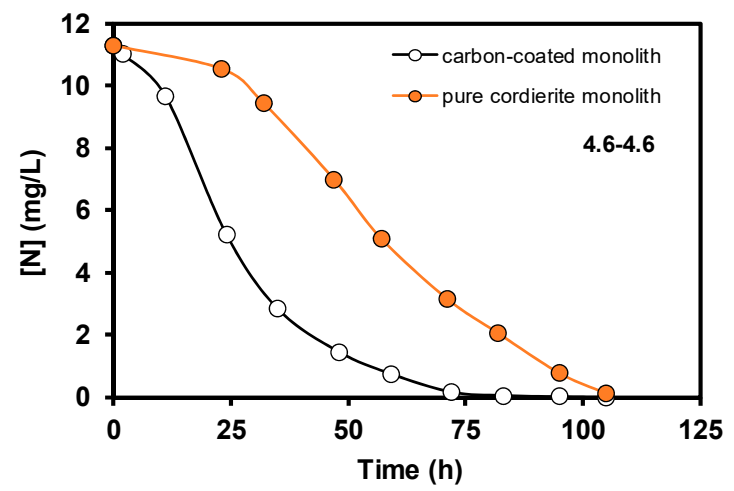

Figure 4. Nitrate elimination curves obtained in conditions 4.6-4.6. Data are expressed as nitrogen concentration. 


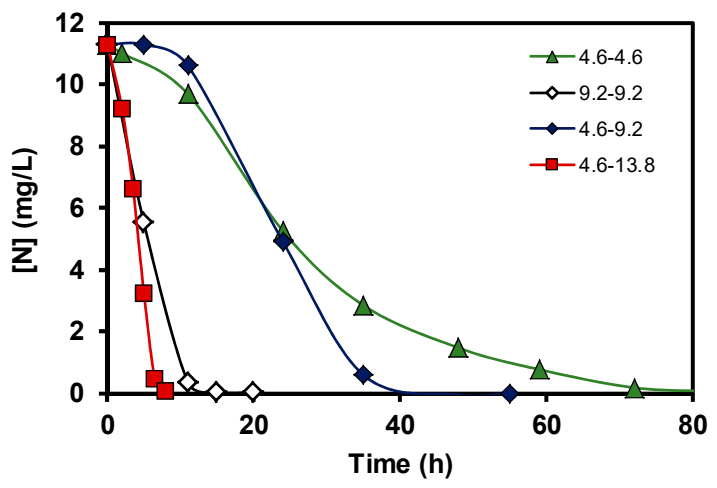

Figure 5. Nitrate elimination curves at different liquid flow velocities. Data are expressed as nitrogen concentration.

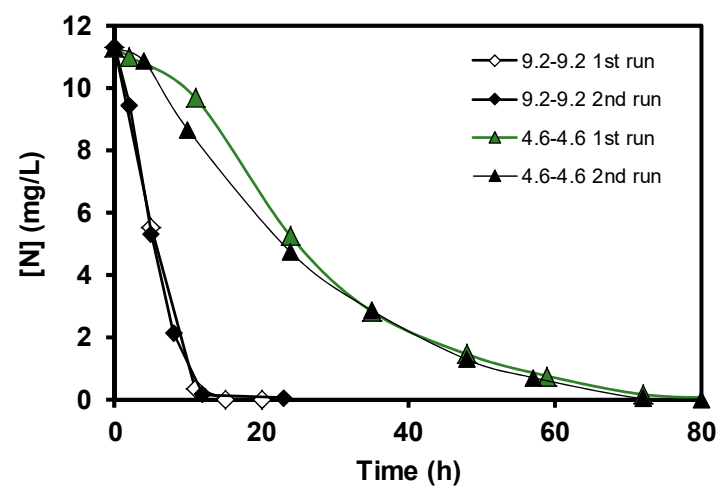

Figure 6. Nitrate elimination curves. First and second consecutive runs. Data are expressed as nitrogen concentration.

Author Contributions: Conceptualization, A.F.P.-C., F.C.-M. and E.B.-G.; methodology, D.E.-I., E.B.-G. and M.I.B.-T.; formal analysis, A.F.P.-C., F.C.-M. and M.I.B.-T.; investigation, D.E.-I. and E.B.-G; writing-review and editing, A.F.P.-C.; supervision, A.F.P.-C. and M.I.B.-T.; project administration, F.C.-M. and E.B.-G.; funding acquisition, E.B.-G. All authors have read and agreed to the published version of the manuscript.

Funding: This research was funded by Junta de Andalucía (Projects: P18-RTJ-2974 and RNM172) and Generalitat Valenciana (contract APOSTD/2019/030).

Conflicts of Interest: The authors declare no conflict of interest.

\section{References}

1. Sawayama, S.; Rao, K.K.; Hall, D.O. Nitrate and phosphate ion removal from water by Phormidium laminosum immobilized on hollow fibres in a photobioreactor. Appl. Microbiol. Biotechnol. 1998, 49, 463. [CrossRef]

2. Zayed, G.; Winter, J. Removal of organic pollutants and of nitrate from wastewater from the dairy industry by denitrification. Appl. Microbiol. Biotechnol. 1998, 49, 469. [CrossRef]

3. Moreno-Castilla, C.; Bautista-Toledo, M.I.; Ferro-Garcia, M.A.; Rivera-Utrilla, J. Influence of support surface properties on activity of bacteria immobilised on activated carbons for water denitrification. Carbon 2003, 41, 1743. [CrossRef]

4. Morales-Torres, S.; Maldonado-Hodar, F.J.; Perez-Cadenas, A.F.; Carrasco-Marin, F. Structural characterization of carbon xerogels: From film to monolith. Microporous Mesoporous Mater. 2012, 153, 24. [CrossRef]

5. Avila, P.; Montes, M.; Miro, E.E. Monolithic reactors for environmental applications: A review on preparation technologies. Chem. Eng. J. 2005, 109, 11. [CrossRef]

6. Kapteijn, F.; Heiszwolf, J.J.; Nijhuis, T.A.; Moulijn, J.A. Monoliths in multiphase catalytic processes-Aspects and prospects. Cattech 1999, 3, 24. 
7. Chaparro-Garnica, C.Y.; Davo-Quiñonero, A.; Bailon-Garcia, E.; Lozano-Castello, D.; Bueno-Lopez, A. Design of Monolithic Supports by 3D Printing for Its Application in the Preferential Oxidation of CO (CO-PrOx). ACS Appl. Mater. Interfaces 2019, 11, 36763. [CrossRef] [PubMed]

8. Davo-Quiñonero, A.; Sorolla-Rosario, D.; Bailon-Garcia, E.; Lozano-Castello, D.; Bueno-Lopez, A. Improved asymmetrical honeycomb monolith catalyst prepared using a 3D printed template. J. Hazard. Mater. 2019, 368, 638. [CrossRef] [PubMed]

9. Pérez-Cadenas, A.F.; Zieverink, M.M.P.; Kapteijn, F.; Moulijn, J.A. Selective hydrogenation of fatty acid methyl esters on palladium catalysts supported on carbon-coated monoliths. Carbon 2006, 44, 173. [CrossRef]

10. Valverde-Sarmiento, C.; Espinosa-Iglesias, D.; Bautista-Toledo, M.I.; Alvarez-Merino, M.A.; MaldonadoHodar, F.J.; Carrasco-Marin, F.; Perez-Cadenas, A.F. Bacteria supported on carbon films for water denitrification. Chem. Eng. J. 2015, 259, 424. [CrossRef]

11. Bautista-Toledo, M.I.; Espinosa-Iglesias, D.; Carrasco-Marin, F.; Perez-Cadenas, A.F.; Maldonado-Hodar, F.J. Influence of the physicochemical properties of inorganic supports on the activity of immobilized bacteria for water denitrification. J. Environ. Manag. 2015, 156, 81. [CrossRef]

12. Ebrahimi, S.; Kleerebezem, R.; Kreutzer, M.T.; Kapteijn, F.; Moulijn, J.A.; Heijnen, J.J.; Van Loosdrecht, M.C.M. Potential application of monolith packed columns as bioreactors, control of biofilm formation. Biotechnol. Bioeng. 2006, 93, 238. [CrossRef] [PubMed]

Publisher's Note: MDPI stays neutral with regard to jurisdictional claims in published maps and institutional affiliations. 